\title{
LATE SUMMER OZONE VARIABILITY IN THE LOWER TROPOSPHERE OF THE EASTERN MEDITERRANEAN
}

\author{
Christoforos Tsamalis ${ }^{1,3 *}$, Alexandros Papayannis ${ }^{2}$, Gerard Ancellet ${ }^{1}$, François Ravetta ${ }^{1}$ \\ ${ }^{I}$ Sorbonne Universités, UPMC Univ. Paris 06, Université Versailles St-Quentin, CNRS/INSU, LATMOS- \\ IPSL, 75252, Paris, France \\ ${ }^{2}$ Physics Department, National Technical University of Athens, 15780, Zografou, Greece \\ ${ }^{3}$ Now at Met Office, Exeter, EX1 3PB, UK, *Email: christoforos.tsamalis@metoffice.gov.uk
}

\begin{abstract}
During the STAAARTE 96 Hellen aircraft campaign the lidar ALTO together with in situ measurements examined the ozone and aerosols variability in the lower troposphere over the Eastern Mediterranean region. Ozone mean value in the free troposphere (FT) measured from ALTO was $48 \mathrm{ppb}$, while it was $45 \mathrm{ppb}$ from in situ observations; the aerosols mean scattering coefficient $(550 \mathrm{~nm})$ was $31 \mathrm{Mm}^{-1}$. The FT ozone distributions of the two instruments are significantly different to distinct sampling. Air masses origin examination using the FLEXPART model for low and high FT ozone observations during late summer indicate that low ozone masses come from Mediterranean/North Africa regions travelling at low altitude, while high ozone masses emanate from Europe's middle or upper troposphere.
\end{abstract}

\section{INTRODUCTION}

In the Mediterranean region air masses with different origin are found creating an atmospheric crossroads. This favours the transport of atmospheric constituents in the region like ozone, its precursors and aerosols, at high variable concentrations, which under the high insolation, especially during the summer period, create an ideal environment for photochemical reactions to take place [1]. Indeed, during summertime an ozone pool is observed over the Eastern Mediterranean free troposphere (FT), which is one of the regions with the highest background levels of tropospheric ozone worldwide [2]. The number of the studies focusing in the FT ozone in the area is limited (e.g. [3]), mainly using either models, which are affected by the emissions uncertainties or satellites, which do not provide the required vertical resolution to observe ozone layers e.g. [4].

\section{THE STAAARTE HELLEN 96 CAMPAIGN}

The STAAARTE (Scientific Training and Access to Aircraft for Atmospheric Research Throughout Europe) Hellen 96 airborne campaign took place during the period 19-26 September 1996 over Greece (Fig. 1, Tab. 1). The main purpose of the campaign was to characterise the ozone variability in the lower troposphere over the region during late summer and to identify the processes that contribute to this variability. The French Fokker 27 medium-range research aircraft (ARAT) realised in total 10 flights flying at an altitude of 3-4.3 km a.s.1. (Fig. 1, Tab. 1).

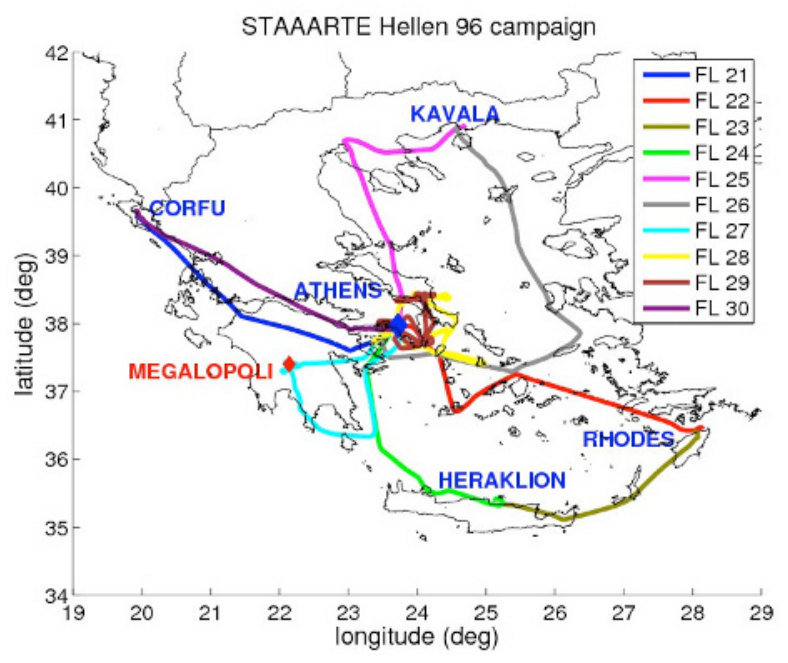

Fig. 1: Flights tracks.

The main instrument on board the aircraft was the lidar ALTO, a UV differential absorption lidar (DIAL) system based on Nd:YAG laser and stimulated Raman scattering in deuterium to generate three wavelengths (266, 289 and $316 \mathrm{~nm}$ ) in order to measure ozone and aerosols profiles [5]. The ALTO optical receiver includes a $40 \mathrm{~cm}$ Cassegrain telescope coupled to a grating 


\begin{tabular}{|c|c|c|c|c|}
\hline Flight & Date & Time (UTC) & Altitude (km) & Path \\
\hline 21 & $19 / 9 / 1996$ & $13: 22-14: 37$ & $3.33 \pm 0.02$ & Corfu - Athens \\
\hline 22 & $21 / 9 / 1996$ & $07: 03-08: 48$ & $3.93 \pm 0.02$ & Athens - Rhodes \\
\hline 23 & $21 / 9 / 1996$ & $10: 30-11: 54$ & $4.23 \pm 0.04$ & Rhodes - Heraklion \\
\hline 24 & $21 / 9 / 1996$ & $13: 15-14: 48$ & $3.02 \pm 0.02$ & Heraklion - Athens \\
\hline 25 & $22 / 9 / 1996$ & $07: 12-09: 02$ & $3.64 \pm 0.02$ & Athens - Kavala \\
\hline 26 & $22 / 9 / 1996$ & $10: 26-12: 45$ & $3.77 \pm 0.15$ & Kavala - Athens \\
\hline 27 & $24 / 9 / 1996$ & $08: 02-10: 06$ & $3.63 \pm 0.03$ & Athens - Megalopoli - Athens \\
\hline 28 & $24 / 9 / 1996$ & $12: 57-15: 12$ & $4.17 \pm 0.19$ & Athens - Euboea - Athens \\
\hline 29 & $25 / 9 / 1996$ & $07: 57-10: 02$ & $3.79 \pm 0.03$ & Athens - Euboea - Athens \\
\hline 30 & $26 / 9 / 1996$ & $06: 56-08: 22$ & $4.25 \pm 0.03$ & Athens - Corfu \\
\hline
\end{tabular}

Tab. 1: Information (flight number, date, flight time, mean altitude with standard deviation and path) about the flights during the STAAARTE Hellen 96 campaign.

spectrometer by a $1.5 \mathrm{~mm}$ diameter fused-silica optical fiber. Two wavelength pairs are used for the ozone observation 266-289 $\mathrm{nm}$ and 289-316 $\mathrm{nm}$, the first for short distances $(0.5-2 \mathrm{~km})$ while the second for longer distances $(1.5-5 \mathrm{~km})$. At near range $(<0.5 \mathrm{~km})$ where the overlap function between the laser beam and the telescope field of view is still range dependant the observations are excluded. ALTO is able to characterise narrow layers $(<0.5 \mathrm{~km})$ with good accuracy $(<5-10 \mathrm{ppb})$. At $316 \mathrm{~nm}$ the ozone absorption can be neglected in the troposphere and the aerosol profile is expressed through the non-dimensional scattering ratio, which is the ratio of total (molecules and aerosols) backscattering to molecular backscattering. Aboard the aircraft there were also in situ instruments measuring ozone (ThermoElectron 49PS with accuracy $1 \mathrm{ppb}$ ) and aerosols scattering coefficient at $550 \mathrm{~nm}$ (MRI 1550B with uncertainty $10 \%$ ).

\section{RESULTS}

Tab. 2 presents the mean values and the range of ozone and aerosols in the FT measured by the in situ instruments. The lower ozone values $(<30$ ppb) encountered during flights 25 and 26, while the higher $(>70 \mathrm{ppb})$ during Flight 24 . Regarding aerosols the lower values were found during flights 23, 28 and 29 (just above $20 \mathrm{Mm}-1$ ) and the higher (>60 Mm-1) during flight 21 due to Saharan dust intrusion (not shown). The distributions of ozone measured in situ and from ALTO in the FT and the aerosols are depicted in Fig. 2.
According to ALTO the ozone mean value is 48 $\mathrm{ppb}$ and slightly lower for the in situ at $45 \mathrm{ppb}$, while the mean aerosols scattering coefficient is $31 \mathrm{Mm}-1$ (with the high value tail being mainly due to the dust event). Interestingly the Ozone distributions are different, with the ALTO one being bimodal and having significantly more ozone measurements in the range 55 to $70 \mathrm{ppb}$. This is mainly due to different sampling of air masses between the two instruments as it can be seen in Fig. 3. During flight 29 ALTO is able to detect an ozone layer at $2.5-3 \mathrm{~km}$, which is not affected by aerosols or clouds as it can be seen by the scattering ratio being almost 1 indicative of molecular scattering only. However, this layer is missed by the in situ instrument measuring higher in the troposphere.

\begin{tabular}{|c|c|c|}
\hline Flight & Ozone (ppb) & Aerosols $\left(\mathbf{M m}^{-1}\right)$ \\
\hline 21 & $48 \pm 9[34,65]$ & $40 \pm 9[29,66]$ \\
\hline 22 & $45 \pm 11[29,63]$ & $35 \pm 1[32,39]$ \\
\hline 23 & $46 \pm 3[42,51]$ & $25 \pm 1[22,29]$ \\
\hline 24 & $61 \pm 9[42,76]$ & $31 \pm 1[27,34]$ \\
\hline 25 & $38 \pm 5[27,46]$ & $35 \pm 5[29,56]$ \\
\hline 26 & $36 \pm 4[28,47]$ & $30 \pm 3[24,39]$ \\
\hline 27 & $47 \pm 3[40,53]$ & $29 \pm 2[26,37]$ \\
\hline 28 & $48 \pm 2[43,53]$ & $27 \pm 4[21,38]$ \\
\hline 29 & $44 \pm 2[38,48]$ & $31 \pm 4[21,41]$ \\
\hline 30 & $39 \pm 2[34,43]$ & $29 \pm 3[23,40]$ \\
\hline
\end{tabular}

Tab. 2: Mean, standard deviation and range [minimum, maximum] of FT values for ozone and aerosols. 

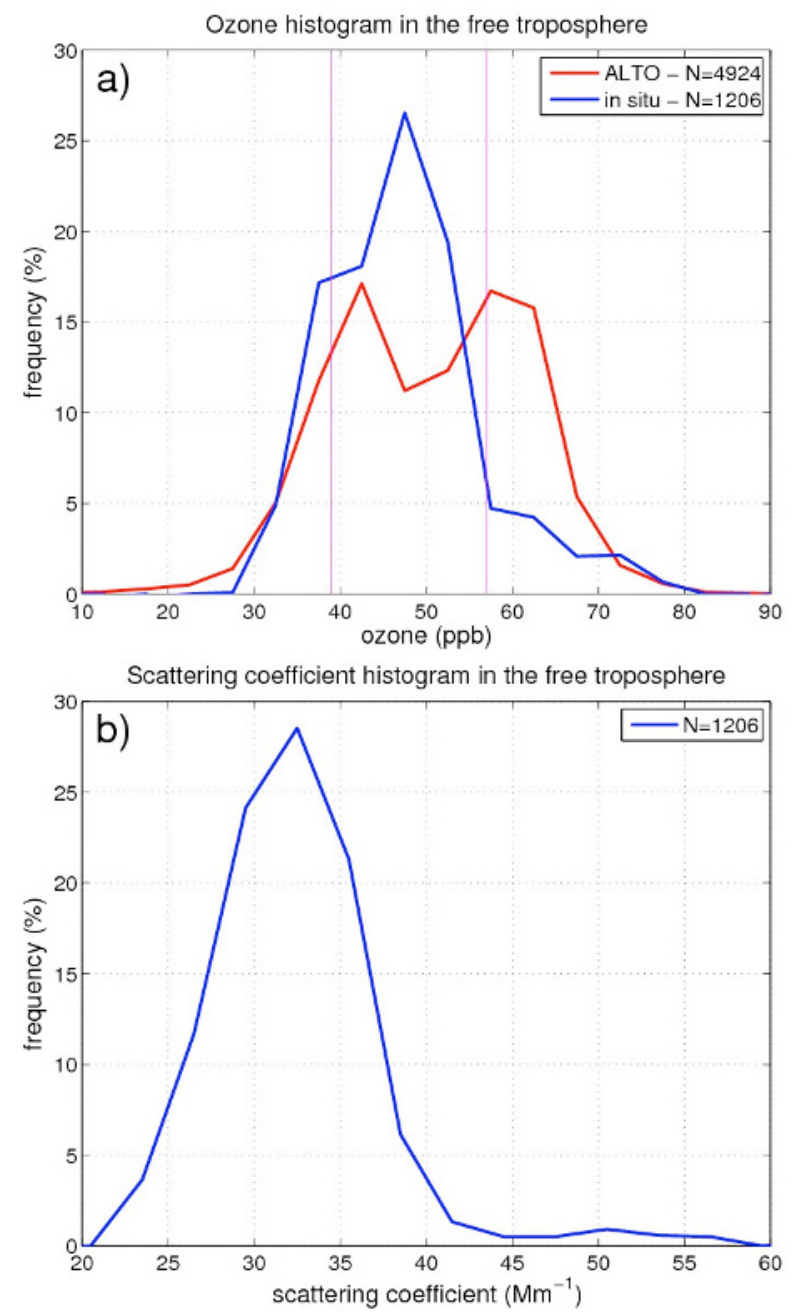

Fig. 2: Histograms of free tropospheric (a) ozone and (b) aerosols from in situ (blue) and ALTO (red) observations.

The origin of the low $(<39 \mathrm{ppb})$ and high $(>57$ ppb) ozone air masses based on the ALTO distribution of Fig. 2a and corresponding to the first and the third quartiles are examined using the FLEXPART model [6]. Fig. 4 shows only air masses at every location when the percentage at this location is larger than $0.1 \%$, in order to have a minimum statistical significance. It can be observed that the air masses characterized by low ozone have either maritime origin (Mediterranean Sea and Atlantic Ocean) or coming from northern Africa while always their mean altitude is below 3 $\mathrm{km}$. This reflects the export of clean maritime or depleted by dust particles air from the local boundary layer.
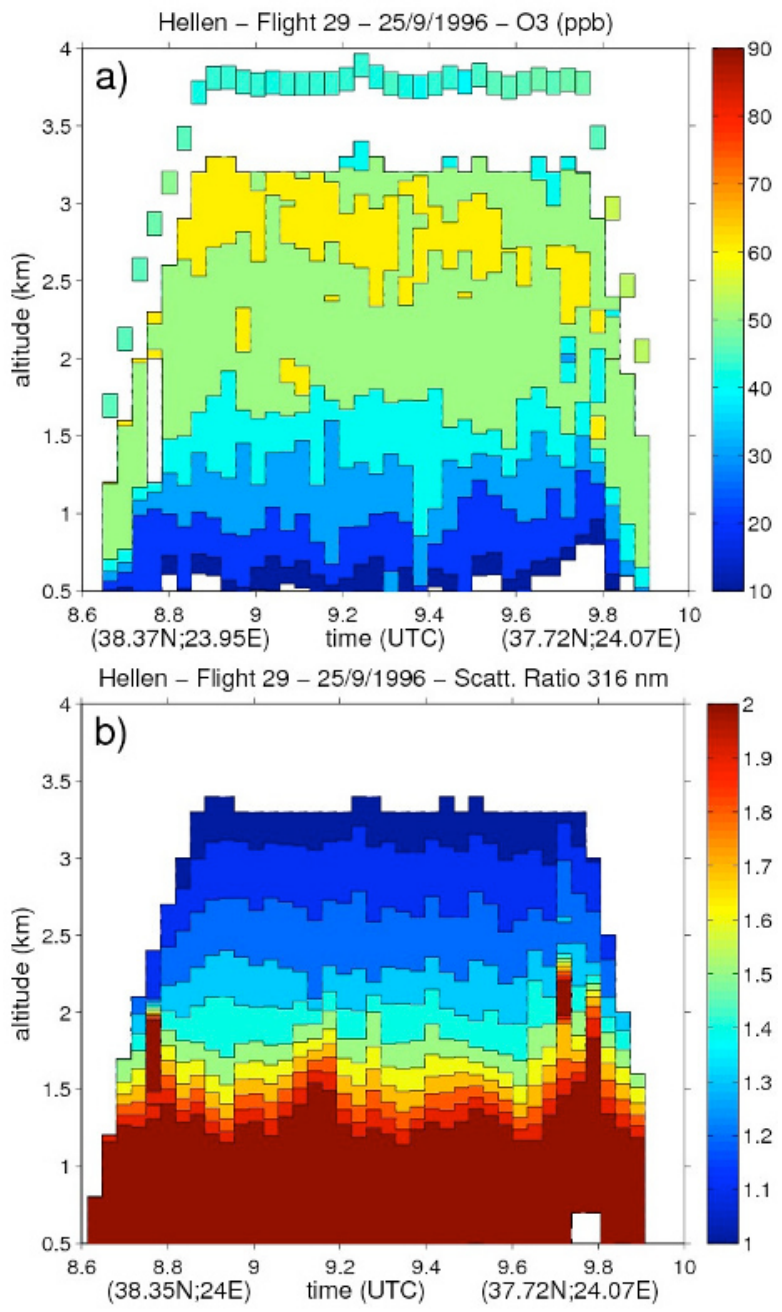

Fig. 3: ALTO measurements of (a) ozone (with the in situ above) and (b) aerosols.

On the other hand, the air masses with high ozone are coming from Europe and their mean altitude is above $4 \mathrm{~km}$ reaching $8 \mathrm{~km} \mathrm{4-5}$ days before their observation. Although, there is no indication from FLEXPART of a stratospheric intrusion within this time interval, their relatively increased potential vorticity points towards old stratospheric masses.

\section{ACKNOWLEDGEMENT}

The STAAARTE Hellen 96 Campaign was financed by the European Union through the Training and Mobility of Researchers (TMR) Programme - Access to Large-scale Facilities/EU DG XH, which is gratefully acknowledged. 

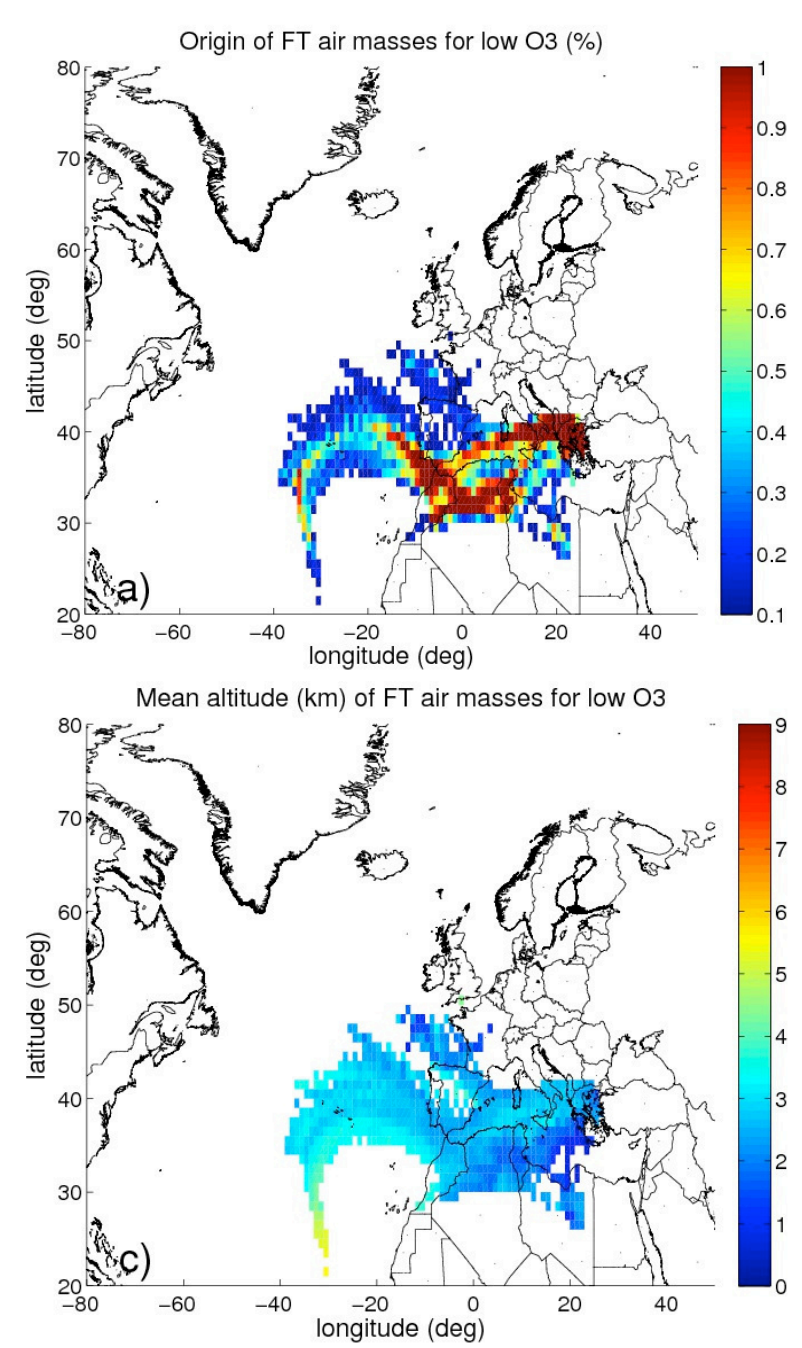

Fig. 4: $(a, b)$ Origin of Free Tropospheric air masses during the campaign and (c, d) mean altitude for low $(<39 \mathrm{ppb})$ and high $(>57 \mathrm{ppb})$ ozone concentrations.

C. Tsamalis is grateful to Eugenides Foundation for financial support.

\section{REFERENCES}

[1] Lelieveld J. et al., 2002: Global air pollution crossroads over the Mediterranean, Science, 298, 794-799.

[2] Zanis P. et al., 2014: Summertime freetropospheric ozone pool over the eastern Mediterranean/Middle East, Atmos. Chem. Phys., 14, 115-132.
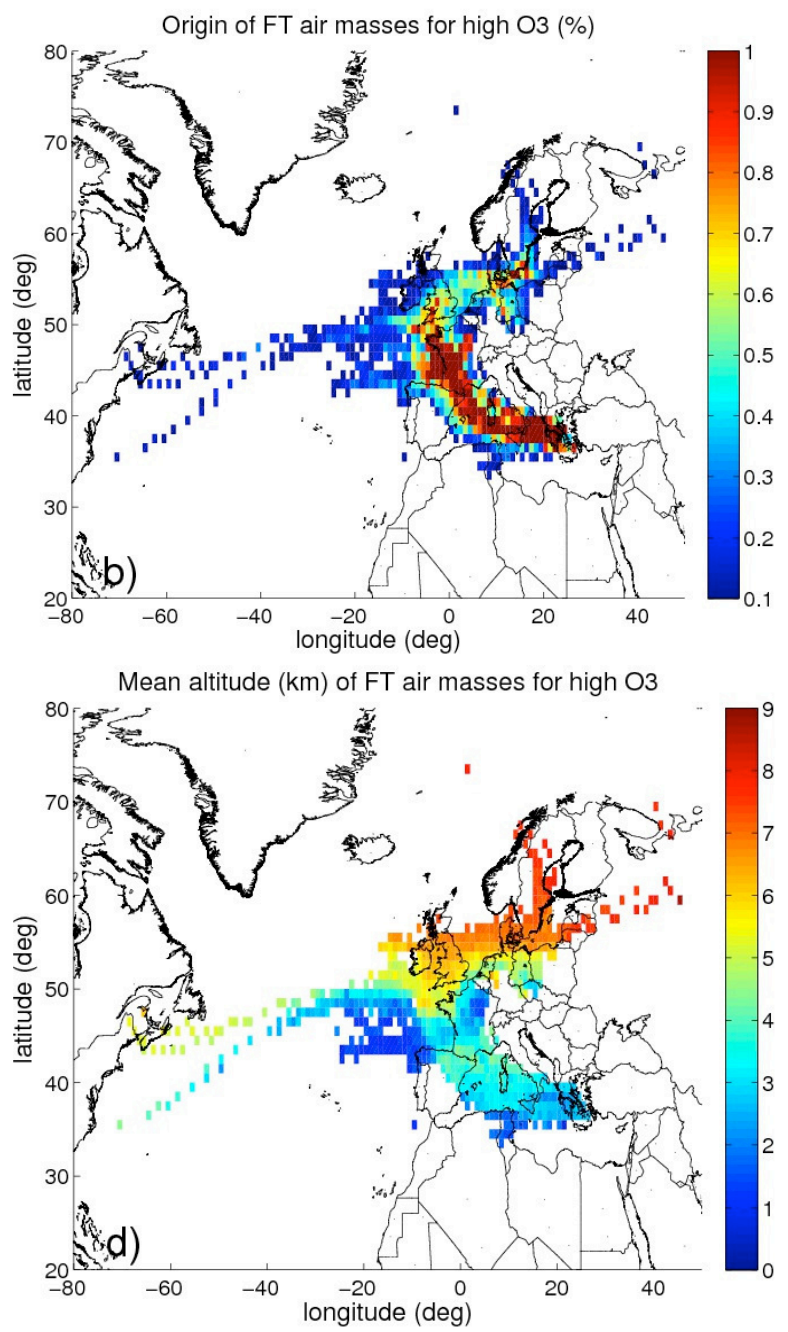

[3] Kalabokas P. D. et al., 2013: Examination of the atmospheric conditions associated with high and low summer ozone levels in the lower troposphere over the eastern Mediterranean, Atmos. Chem. Phys., 13, 10339-10352.

[4] Safieddine S. et al., 2014: Summertime tropospheric ozone assessment over the Mediterranean region using the thermal infrared IASI/MetOp sounder and the WRF-Chem model, Atmos. Chem. Phys., 14, 10119-10131.

[5] Ancellet G. and Ravetta F., 1998: Compact airborne lidar for tropospheric ozone: description and field measurements, Appl. Opt., 37(24), 55095521.

[6] Stohl A. C. et al., 2005: Technical note: The Lagrangian particle dispersion model FLEXPART version 6.2, Atmos. Chem. Phys., 5, 2461-2474. 